Di. $\left\{\begin{array}{l}\text { Revista internacional } \\ \text { de Historia } \\ \text { de la Comunicación }\end{array}\right.$

\title{
LA REPRESENTACIÓN DE LA MUJER EN LAS RELACIONES DE SUCESOS
}

DOI: http://dx.doi.org/10.12795/RiHC.2014.i02.01

Abel Iglesias Castellano

Universidad de Alcalá

abeliglesiascastellano@yahoo.es

Recibido, 29 de mayo de 2013

Aceptado, 29-7-2013

Resumen: El presente trabajo es un estudio de la representación de la mujer en relaciones de sucesos impresas en España entre los siglos XVI y XVIII. Principalmente, analizamos las estrategias discursivas que son empleadas por este tipo de textos para trasladar a los lectores una determinada imagen de la mujer. Abordamos la cuestión de la importancia de la oralidad en la transmisión de los pliegos de cordel, así como la disyuntiva entre la coacción ejercida por el autor y la libertad del lector.

Palabras clave: relaciones de sucesos, mujeres, representación, Nueva Historia Cultural.

\footnotetext{
${ }^{1}$ Este trabajo ha sido realizado en el marco de la "Ayuda de Iniciación en la Actividad Investigadora" (2012-2013), que me fue concedida por la Universidad de Alcalá de Henares (300M00.541.A645.27.). Quiero agradecer al profesor Dr. Juan Ignacio Pulido Serrano su labor tutorial en el desarrollo de la mencionada ayuda, así como los comentarios y sugerencias del profesor Dr. Antonio Castillo Gómez.
} 
Abstract: This paper is a study of the woman's representation in the Spanish news pamphlets printed between $16^{\text {th }}-18^{\text {th }}$ centuries. Above all, we analyse speech strategies used in this kind of texts to give the readers a certain image of the woman. We see how important orality was in the communication of tales. In addition, we observe the dilemma between the author's coercion and the readers' freedom.

Keywords: news pamphlets, women, representation, New Cultural History.

\section{Introducción}

Peter Burke, en su obra ¿Qué es la historia cultural?, incluye las historias de las representaciones de las mujeres dentro del concepto de representación (Burke, 2005: 84), término clave de la denominada Nueva Historia Cultural. A través del presente trabajo pretendemos abordar la cuestión de la representación de la mujer en una tipología textual determinada: las relaciones de sucesos, documentos históricos pertenecientes a la "literatura de cordel" ${ }^{2}$. Según Nieves Pena Sueiro, las relaciones de sucesos son "textos ocasionales en los que se relatan acontecimientos con el fin de informar, entretener y conmover al receptor. Habitualmente consideradas como antecesoras de la prensa actual, cubren todos los aspectos tratados por ésta en sus diferentes secciones (...), pero con la salvedad que cada Relación suele referir un solo acontecimiento" (Pena Sueiro, 2001: 43) ${ }^{3}$. En base a esta definición, evidentemente, concluimos que no todos los pliegos de cordel son relaciones de sucesos ${ }^{4}$.

\footnotetext{
${ }^{2}$ En los inicios del estudio de las relaciones de sucesos, destacan dos monografías; por un lado, el Ensayo sobre la literatura de cordel, de Julio Caro Baroja (Caro Baroja, 1969); y, por otro lado, la obra de María Cruz García de Enterría titulada Sociedad y poesía de cordel en el Barroco (García de Enterría, 1973). Actualmente, contamos con una gran cantidad de estudios que abordan el fenómeno de las relaciones (véase el repertorio bibliográfico recogido en la página web www.bidiso.es). En el apartado de los catálogos, fue fundamental la tarea de Mercedes Agulló Cobo, autora del repertorio que lleva por título Relaciones de sucesos. I, Años 1477-1619 (Agulló Cobo, 1966). Con el paso de los años han sido muchos los catálogos publicados, entre los que sobresale el Catálogo de pliegos sueltos poéticos de la Biblioteca Nacional: siglo XVII, obra colectiva dirigida por María Cruz García de Enterría y Julián Martín Abad (García de Enterría y Martín Abad, 1998). Además, la Biblioteca del relacionero, de Consuelo Gonzalo García (Gonzalo García, 2010) es una obra fundamental para todo aquel que se acerque a la investigación de las relaciones de sucesos.

${ }^{3}$ Hay que ser cautos a la hora de hablar de las similitudes entre relaciones de sucesos y periodismo. María Sánchez-Pérez cree que hay notables diferencias entre las relaciones de sucesos y el desarrollo posterior del periodismo, puesto que aquellas van más allá de lo puramente informativo, contando también con una intención literaria (Sánchez-Pérez, 2008: 19-20).

${ }^{4}$ Consideramos que no siempre es fácil establecer si un determinado pliego es una relación de sucesos o no lo es. A priori, esta distinción habría que realizarla en base a la veracidad del acontecimiento narrado. No obstante, creemos que no es tan sencillo; por ejemplo, una relación puede partir de un caso real,
} 
La presente investigación está basada en un corpus documental formado por once relaciones de sucesos: cinco pertenecen a la Biblioteca Nacional de España, otras cinco son albergadas por la Biblioteca de Catalunya, mientras que solo una de ellas ha sido consultada a través del Catálogo y Biblioteca Digital de Relaciones de Sucesos. Tras realizar un rastreo de dichos catálogos, hemos considerado que estos ejemplares son los más representativos para llevar a cabo nuestro estudio. Están situados entre los siglos XVI y XVIII, periodo de máximo desarrollo de este tipo de textos. Asimismo, hemos optado por un número relativamente reducido de pliegos porque, aunque reconocemos los logros de la historia cuantitativa del libro y de la lectura, nuestros propósitos son en este caso cualitativos. Todas estas fuentes han sido consultadas in situ, excepto la relación del catálogo digital ${ }^{5}$.

Una de las tres vertientes que Roger Chartier ha establecido para el término "representación" es la siguiente: "las representaciones colectivas que incorporan en los individuos las divisiones del mundo social y que organizan los esquemas de percepción y de apreciación a partir de los cuales clasifican, juzgan y actúan éstos" (Chartier, 1993a: 101). Las representaciones de la mujer en las relaciones de sucesos forman parte del discurso construido en torno a ésta, entendiendo el término discurso "como la doctrina o ideología que trata de reglamentar y sistematizar el funcionamiento de una sociedad; es decir, el conjunto de textos que la clase dominante o las personas socialmente autorizadas elaboran con objeto de ordenar las relaciones y prácticas sociales" (Castillo Gómez, 2005: 23). Los conceptos “discurso" y "poder" están íntimamente relacionados, puesto que el texto escrito y el habla son dos medios empleados para tratar de ejercer un control mental sobre las personas (Van Dijk, 2001: 40-41).

El Análisis del Discurso es una herramienta que puede ser utilizada por los historiadores para avanzar en el conocimiento de las sociedades pretéritas. No obstante, no pretendemos reducir nuestro artículo a un análisis del discurso de aquellos documentos de la Edad Moderna que representan la imagen de la mujer. Simplemente, creemos que el empleo de una serie de conceptos provenientes de esta disciplina es positivo para nuestros intereses ${ }^{6}$. Creemos que en las relaciones de

pero no por ello todo lo narrado tiene que ser necesariamente cierto. Así, nosotros preferimos poner el acento en dos cuestiones: la apariencia de veracidad y el aspecto noticioso. En este orden de cosas, Roger Chartier ha señalado que "en efecto, es posible que se adhirieran [los lectores] a los efectos de realidad ordenados en los textos sin por ello creer que lo que leen es verdadero, incluso sabiendo muy bien que no lo es para nada" (Chartier, 1993b: 231).

${ }^{5}$ Al final del presente trabajo hemos incluido la relación de las fuentes documentales consultadas.

6 "El analista del discurso trata su corpus como el registro (texto) de un proceso dinámico en el cual el hablante/escritor utiliza el lenguaje como instrumento de comunicación en un contexto para expresar significados y hacer efectivas sus intenciones (discurso). Trabajando sobre estos datos, el analista intenta describir las regularidades encontradas en las realizaciones lingüísticas que emplea la gente para comunicar esos significados e intenciones" (Brown y Yule, 1993: 47). Una de las vertientes de esta disciplina es el análisis social del discurso, que, además de tratar de "comprender la relación entre las 
sucesos pueden detectarse una serie de regularidades en sus estrategias discursivas, lo cual responde, en último término, a la necesidad de facilitar la lectura al destinatario de las mismas, así como al objetivo de imponer un determinado mensaje.

Por lo dicho hasta aquí, ya puede deducirse que nos situamos en el terreno de la Nueva Historia Cultural y, más concretamente, en la Historia de la Cultura Escrita, disciplina que, en líneas generales, se ocupa del estudio de la escritura en lo referente a las funciones y a las prácticas materiales (Castillo Gómez, 2005: 19) ${ }^{7}$.

\section{La importancia de la oralidad en la transmisión de las relaciones de sucesos}

El contexto en el que se desarrolla la percepción de lo escrito es uno de los ámbitos de estudio que debe ser abordado por la Historia de la Cultura Escrita. Con ello nos referimos a los procedimientos o mecanismos que son empleados para hacer llegar un determinado impreso o manuscrito al destinatario del mismo, así como a las condiciones en las que se produce la percepción. Aunque nuestro corpus de textos está formado por un conjunto de pliegos sueltos impresos, la representación de la mujer contenida en éstos no fue transmitida únicamente a través de la palabra escrita. La oralidad constituyó un canal de transmisión complementario, de tal manera que los hombres y las mujeres de la España Moderna no sólo accedieron a esta literatura efímera a través de los signos gráficos que contemplamos hoy día nosotros, sino que también lo hicieron mediante la palabra hablada. Numerosos investigadores han apuntado en esta dirección. María Cruz García de Enterría ha aludido a "la extensión del fenómeno bien conocido de la literatura oral" (García de Enterría, 1999: 350), y Roger Chartier ha visto en la lectura en voz alta un rasgo característico de los siglos modernos: "Representado o postulado como una de sus lecturas implícitas por ciertos

estructuras del discurso y los contextos sociales", aborda la cuestión de "las representaciones mentales socialmente adquiridas y compartidas que definen a las culturas y los grupos, y que organizan y supervisan sus creencias además de sus prácticas sociales y discursos" (Van Dijk, 2001: 64).

\footnotetext{
${ }^{7}$ Según Pablo Vázquez Gestal, dos de las características de la Nueva Historia Cultural -surgida en la década de los ochenta del pasado siglo- son la utilización de nuevas fuentes y "una relativamente nueva teoría del conocimiento racional que exige al intelectual de hoy zafarse y trascender del texto escrito" (Vázquez Gestal, 2001: 158-162). En este mismo sentido, Peter Burke afirma que los estudios culturales no deben volver en ningún caso a la literalidad positivista (Burke, 2005: 154). La Nueva Historia Cultural no es simplemente una moda historiográfica, sino que nos permite ampliar el conocimiento histórico (Ugarte, 2005: 283). Para una visión general sobre la posición que ocupa la Historia de la Cultura Escrita respecto a la Nueva Historia Cultural, véase el reciente trabajo de Carlos Alberto González Sánchez (González Sánchez, 2012).
} 
textos literarios, leer en voz alta (y escuchar leer) es una práctica frecuente de las sociedades del Antiguo Régimen" (Chartier, 1992: 124) ${ }^{8}$.

En esta misma línea, podemos extraer de nuestra selección de textos una serie de referencias implícitas a la lectura en voz alta. Por ejemplo, en una Verdadera relación ${ }^{9}$, que relata la historia de una señora que es cortejada por dos hombres, hallamos unos versos que nos remiten a una situación en la que la oralidad está presente en la transmisión del mensaje: "Presten atención un rato,/a este sonoro instrumento,/cuya acorde melodía/me ha de acompañar los ecos/con sus agradables voces;/pues es el divertimiento,/que causan sus claras cuerdas,/de todos el más supremo:/a cuya armoniosa voz/diré el más gracioso cuento" (BC, F. Bon. 4380 $)^{10}$.

Los analistas del discurso Gillian Brown y George Yule han definido las "señales paralingüísticas" como "el registro de los efectos del "tono de voz» (así como la expresión facial y los sistemas de posturas y gestos)", estando dichas señales a disposición del hablante (Brown y Yule, 1993: 23) ${ }^{11}$. A diferencia de los etnógrafos, los historiadores no podemos registrar en una grabadora o en una cámara cinematográfica esas señales paralingüísticas, puesto que la variable tiempo nos lo impide. No obstante, ello no es óbice para que podamos considerar que esas señales efectivamente entraban en juego cuando los ruiseñores populares ${ }^{12}$ se disponían a vender su mercancía. Un romance escrito por Juan de Mendoza -que da cuenta de la historia de una mujer llamada Fénix que se convirtió en capitán de bandoleros- abre la narración de los hechos con las siguientes palabras: "Rompa en sonoros acentos,/diga en voces elevadas,/entone en claros clarines,/cante en dulces consonancias,/la fama un raro suceso/a que yo sus circunstancias/me aplico a decir también;/oigan, que es caso que pasma" (BC, F. Bon. 11797). Las referencias a los "sonoros acentos", a las "voces elevadas", a las "dulces consonancias" y a la entonación constituyen una especie de guía acerca de cómo tenía que recitarse la historia desplegada a través de los versos del romance. A partir del concepto "señales paralingüísticas" entendemos mejor las reflexiones de Juan Gomis Coloma, quien considera que la mediación Ilevada a cabo por los ciegos "permite afirmar que los pliegos de cordel se publicaban dos

\footnotetext{
${ }^{8}$ Además, son fundamentales los trabajos realizados por Margit Frenk, como por ejemplo su "Ver, oír, leer...", en el que es especialmente interesante el tratamiento de la polisemia de los términos "leer", "oír" y "ver" (Frenk, 1984). La lectura colectiva permitió una mayor difusión de los textos escritos durante la Edad Moderna (Espejo Cala, 2000: 22).

${ }^{9}$ Dado que los objetivos del presente trabajo no entran en los terrenos filológico ni paleográfico, hemos actualizado la ortografía a la hora de transcribir los documentos.

${ }^{10}$ BC (=Biblioteca de Catalunya), F. Bon. (=Folletos Bonsoms).

${ }^{11}$ Teun A. van Dijk incluye este tipo de acciones ("las gesticulaciones, las expresiones faciales y los movimientos del cuerpo") en lo que él denomina "contexto" (Van Dijk, 2001: 35).

12 Los ciegos y los buhoneros fueron los principales vendedores de los pliegos sueltos (Arroyo Rodríguez, 1999: 247). También eran vendidos en los propios establecimientos de los impresores, tal y como se indica en el colofón de muchos de ellos.
} 
veces: una mediante la impresión y otra mediante el voceo, la recitación o el canto" (Gomis Coloma, 2010: 304-305). Además, esa interpretación por parte de los vendedores de los papeles influiría en las aprehensiones de los receptores; es decir, para responder a la pregunta ¿cómo llevaron a cabo los destinatarios la aprehensión de los impresos?, hay que tener en cuenta el papel desempeñado por los vendedores.

Las gentes de la Edad Moderna eran conscientes de la importancia de los intermediarios, tal y como puede apreciarse en el prólogo que hace Lucas Rodríguez a su Romancero historiado (1582), donde plasma su preocupación ante los cambios que podía sufrir la obra debido a la transmisión oral (García de Enterría, 1988: 100).

Según Teun A. van Dijk, uno de los elementos que forman parte del contexto de los discursos es el marco, el cual se refiere a aspectos como el tiempo, el lugar o la posición del hablante (Van Dijk, 2001: 34). Es indudable que buena parte de la recepción de las relaciones de sucesos se producía en el espacio público, por lo que en este caso nos movemos en el terreno de la sociabilización. La lectura pública y compartida de los folletos también influiría en las significaciones que los lectores otorgarían a éstos, tal y como analizaremos en el siguiente apartado.

\section{Las estrategias discursivas de las relaciones de sucesos}

Los autores de las relaciones de sucesos -al igual que ocurre con cualquier otro texto escrito y con la comunicación oral- movilizan una serie de estrategias discursivas; es decir, un conjunto de procedimientos o mecanismos que buscan dirigir o coaccionar la lectura llevada a cabo por el destinatario de las mismas ${ }^{13}$. En este orden de cosas, haremos referencia a cuatro conceptos clave: la idea de guión, la utilización de una serie de lugares comunes, la noción de personaje principal y el recurso al sensacionalismo.

La utilización de lo que hemos denominado "estrategias discursivas" está condicionada por las características del público de los pliegos de cordel, así como por el lugar de recepción del mensaje, el cual, como hemos indicado más arriba, era fundamentalmente el espacio público. Evidentemente, las implicaciones de una práctica lectora efectuada colectiva o públicamente no son las mismas que las de una

\footnotetext{
${ }^{13}$ El concepto "estrategias discursivas" es empleado por Patrick Begrand en un artículo titulado Las figuras del renegado y del mártir, metáforas del infierno y del paraíso (Begrand, 2008: 30). El término "coacción" es utilizado por Roger Chartier en su escrito "Textos, impresos, lecturas" (Chartier, 1993b: $55)$.
} 
lectura privada. Mientras que la primera facilita el intercambio de opiniones, la segunda conlleva un ambiente más propicio para la reflexión individual. Los principales destinatarios de estas relaciones de sucesos eran los grupos populares ${ }^{14}$, los cuales, en general, tenían una competencia lectora reducida o nula ${ }^{15}$. Tanto los niveles de alfabetización de los lectores/oyentes como el medio en el que tenía lugar la recepción influirían en la apropiación de los impresos por parte de los destinatarios.

Los guiones son "secuencias estereotipadas de acontecimientos" (Brown y Yule, 1993: 300). En algunas de las relaciones de sucesos que forman parte del corpus que estamos analizando, podemos encontrar un guión bastante similar. En líneas generales, el planteamiento de los hechos está estructurado en tres grandes secuencias. En primer lugar, hallamos una situación de tranquilidad, feliz o placentera. Ésta da paso a una sucesión de acontecimientos negativos. Por último, las situaciones desastrosas cesan y se produce el arrepentimiento y/o castigo de la protagonista de los hechos.

La Verdadera relación, y curioso romance, que declara la vida, y atrocidades de una valiente mujer llamada Fénix comienza con unos versos que describen el amor recíproco entre la protagonista y un hombre: "Declarose con Don Juan,/Fénix, y sin que la raya/del recato se pasase,/le dio a entender que le amaba" (BC, F. Bon. $11797)^{16}$. En el Curioso romance, en que se da cuenta de un maravilloso suceso, y caso prodigioso, que sucedió en la ciudad de Viterbo se presenta una situación similar: Camila, "a los diez y siete años/era hechizo de un mancebo (...)/Paseábale la calle,/escribiole muchos versos,/muchas músicas le daba,/costole muchos paseos" $(B N E, V E 113 / 13)^{17}$. Asimismo, una mujer casada residente en México cambió su feliz matrimonio por una vida errante cuando se enamoró de un soldado, según una relación publicada en Málaga (BNE, VE 1364/7) ${ }^{18}$. Por último, una de las primeras

\footnotetext{
${ }^{14}$ Armando Petrucci dice que el "público potencial" de los avisos impresos era "de extracción y de culturas medias o medio bajas: los mercaderes, titulares de bancos, comerciantes, tenderos, artesanos, militares y profesionales" (Petrucci, 1999: 147).

${ }^{15}$ La realidad social es compleja respecto a los niveles de alfabetización. Armando Petrucci establece seis categorías de alfabetizados (Petrucci, 2002: 28-30). Es decir, una estricta diferenciación entre alfabetizados y analfabetos no es totalmente correcta.

${ }^{16}$ Ya los moralistas del siglo XVI -como Juan Luis Vives, Fray Luis de León y Juan Pérez de Moyapresentaban la castidad como la virtud más importante de las mujeres (Walthaus, 1993: 72).

${ }^{17}$ BNE (=Biblioteca Nacional de España), VE (=Varios Especiales).

18 Durante la Edad Moderna hubo una situación de desigualdad en cuanto a la consideración del adulterio, de tal manera que se consideraba que el hombre solo infringía la ley y el sacramento, mientras que la mujer también atentaba contra la familia y los usos sociales (López Cordón, 1998: 127). Pedro Luis Lorenzo Cardoso señala que el adulterio era la ofensa más grave que un hombre podía recibir de una mujer en el siglo XVII. Tanto era así que la Nueva Recopilación de 1567 permitía que el marido ejecutase a su esposa y al amante de ésta siempre y cuando les cogiera in fraganti. No obstante, en muy pocas ocasiones se ponía en práctica lo permitido por la legislación (Lorenzo Cardoso, 1989: 133). Con todo, entre los papeles del Consejo Supremo de Aragón hallamos un caso que refleja una cierta permisividad social ante los asesinatos que cometían los maridos sobre sus mujeres cuando éstos
} 
estrofas de la Curiosa jácara nueva es una descripción de la bella Antonia de $\mathrm{Paz}^{19}$ : “Era hermosa por extremo,/de donoso brío, y arte" (BNE, MSS 18108) ${ }^{20}$.

Estas cuatro placenteras situaciones dejan paso rápidamente a una sucesión de acontecimientos desastrosos. En primer lugar, Don Félix, enamorado de Fénix, asesina a Don Juan, lo que provoca la ira de aquella, que decide matar al verdugo de su amante. Posteriormente, Fénix protagoniza actos atroces, como asesinatos y violaciones (BC, F. Bon. 11797). En otra composición, la tía de Camila se opone a la relación amorosa que su sobrina mantenía con un mancebo, por lo que "le dispuso un casamiento,/igual a su calidad"21. Tras celebrarse la boda, Camila asesina a su esposo y a su propia tía. Finalmente, se casa en Constantinopla con un turco, a quien pide que asesine a todos los cristianos que tenía en cautividad (BNE, VE 113/13). En el tercer relato, la adúltera mexicana mata a su marido y acusa al soldado de dicho acto, por lo que éste es condenado a ser "arcabuceado" (BNE, VE 1364/7). Por último, Antonia de Paz comete el error de ceder a las promesas de matrimonio de Pedro Alfonso: "Rompió la puerta del jardín,/haciendo al honor ultraje". Ante el incumplimiento de la palabra de su amado, Antonia le asesina y descuartiza (BNE, MSS 18108)22.

Todas estas atrocidades finalizan con el castigo y/o arrepentimiento de sus protagonistas. Fénix y Camila presencian un milagro, lo que provoca el ingreso de la primera en un convento (BC, F. Bon. 11797$)^{23}$ y el suicidio de la segunda (BNE, VE 113/13). El relato de la asesina de México también se cierra con un acontecimiento milagroso: el soldado es arcabuceado, pero "en el pecho del paciente/las balas

habían estado "motivados" por una situación de adulterio. Así se explicaba Francisco Aybar en 1677: "suspenda V.M. el rigor de la justicia por haber matado a mi mujer, adúltera, y tener el deber de mantener a cinco hijos, un padre anciano y una hacienda"; finalmente, este asesino consiguió su propósito (Ortega, 1989: 176-177).

${ }^{19}$ Podemos incluir esta jácara -y las demás empleadas a lo largo del presente trabajo- en lo que Elena Di Pinto denomina "jácaras de sucesos", las cuales constituyen una "modalidad a medio camino entre la jácara propiamente dicha y la relación de sucesos" (Di Pinto, 2010: 217). Creemos que es así porque dicha composición trata de mostrar una apariencia de material noticioso.

${ }^{20}$ MSS (=Manuscritos).

${ }^{21}$ Mariló Vigil ha destacado la vertiente económica del matrimonio del Antiguo Régimen: “En la condena reiterada de los moralistas de que las jóvenes eligieran marido hay una defensa de la sociedad estamental. Si se casaban por su cuenta no es seguro que lo hicieran dentro de su nivel social" (Vigil, 1986: 80-82).

${ }^{22}$ Entre los papeles del Archivo Histórico Municipal de Almansa, la investigadora Manuela Asensio Rubio encontró un proceso judicial relativo a un caso de incumplimiento de palabra de casamiento que data del año 1677. Sebastián Malagón prometió a Bernarda Jiménez casarse con ella; tras gozarla, no cumplió su palabra, por lo que fue denunciado por el padre de la doncella. Sebastián fue encarcelado, dictaminándose que no obtendría la libertad hasta que no aceptase cumplir su promesa (Asensio Rubio, 1988). Sostenemos que no hay una separación total entre la representación del mundo y la situación social realmente dada. Más bien, ambas categorías se influyen mutuamente.

${ }^{23}$ Según la moral de la época, el ingreso en un convento era uno de los cuatro estados naturales de la trayectoria vital de las mujeres. Los otros tres eran: la etapa como doncella, el acceso al matrimonio y la viudedad (Vigil, 1986: 18, 92-93 y 198-199). 
quedaron juntas,/hechas plastas, sin pasarle,/ni dañarle en cosa alguna" (BNE, VE 1364/7). Antonia de Paz confiesa el crimen y es condenada a la horca (BNE, MSS 18108). Por tanto, creemos que Henry Ettinghausen está en lo cierto cuando dice que, realmente, no había malas noticias, ya que incluso las más sensacionalistas se convertían en buenas noticias (Ettinghausen, 2012: 157).

Más allá de la utilización de guiones, hay casos en los que constatamos una contaminación argumental entre dos relaciones diferentes. Dos pliegos sueltos conservados actualmente en la Biblioteca de Catalunya presentan dos tramas muy parecidas. Se trata del Nuevo, y curioso romance, en que se declaran las atrocidades de Sebastiana del Castillo (BC, F. Fon. 11889) y de la Jácara nueva, en que se refiere, y da cuenta de veinte muertes que [hizo] una doncella llamada Doña Teresa de Llanos (BC, F. Bon 20213$)^{24}$. La primera de las relaciones relata cómo Sebastiana del Castillo asesina a sus padres y a sus hermanos porque éstos la habían encerrado con el objetivo de mantenerle alejada de su amante, Juan González del Pino ${ }^{25}$. En la segunda composición, Doña Teresa de Llanos asesina a sus hermanos porque éstos habían matado a su amado. En este caso, la mujer está bajo la tutela de sus hermanos porque sus padres ya habían fallecido. En los dos impresos, la protagonista de los hechos se viste con ropas masculinas para hacerse pasar por un hombre ${ }^{26}$. Ambas mujeres son condenadas a muerte, pero, mientras que en el caso de Sebastiana del Castillo la sentencia es ejecutada, Doña Teresa de Llanos es perdonada gracias a la intervención de algunos hombres de alto rango. En base a los diferentes puntos en común que tienen ambos relatos -más allá de las discrepancias en cuanto a nombres, lugares y situaciones-, consideramos que puede hablarse de una contaminación argumental entre ambos. Lo más interesante al respecto, bajo nuestro punto de vista, es que estos impresos resultarían sumamente familiares para sus destinatarios, lo que facilitaría enormemente su lectura.

\footnotetext{
${ }^{24}$ Existen diferentes ediciones y versiones tanto de la historia de Sebastiana del Castillo como de la de Doña Teresa de Llanos, tal y como puede comprobarse al hacer un simple rastreo por el catálogo de la Biblioteca Nacional de España. Como se ha indicado, nosotros hemos optado por tomar una determinada publicación de cada una de ellas, para así hacer un bosquejo de la posible contaminación argumental entre ambos relatos. Por tanto, queda fuera de nuestros propósitos (debido, entre otras cosas, a la limitación espacial) hacer un estudio comparativo de las distintas ediciones y versiones de cada una de las historias.

${ }^{25}$ Juana Rosa Suárez Robaina, en su monografía sobre la imagen del personaje femenino proyectado en el romancero tradicional, dice que Sebastiana del Castillo pertenece a lo que denomina "mujer perversa", uno de los cuatro "tipos de actuación del personaje literario femenino" (Suárez Robaina, 1993: 23-48).

${ }^{26}$ La mujer vestida de hombre fue un recurso habitual del teatro lopesco (Walthaus, 1993: 75). Para una visión general del travestismo en la literatura áurea, véase la obra de María José Porro Herrera Mujer "sujeto"/mujer "objeto" en la literatura española del Siglo de Oro, donde recuerda que "la condición varonil en el tiempo que nos ocupa, no conlleva el matiz despectivo que encierra en la actualidad, antes bien, suponía un elogio con el que se reconocía el valor, el amor y el prestigio de determinadas mujeres" (Porro Herrera, 1993: 121-129).
} 
Incluso hay casos en los que distintos impresores publicaron la misma relación de sucesos. La Biblioteca de Catalunya alberga en sus fondos dos ediciones barcelonesas de la Jácara nueva, en que se refiere un lastimoso caso, que sucedió a una doncella de la ciudad de Trujillo, una impresa por los herederos de Juan Solís (BC, F. Bon. 4364) y otra por Francisco de Ifern y Oriol (BC, F. Fon 4455). La única variación entre ambas es la inclusión de unos grabados xilográficos diferentes, aunque de temática similar. La primera tiene dos grabados situados debajo del título: a la izquierda hay una mujer de pie, atada a un árbol y con el torso desnudo; y a la derecha hay un cazador acompañado de un perro. En la edición de Francisco de Ifern y Oriol, los personajes han intercambiado su posición con respecto a la otra edición; además, la mujer está sentada.

La lectura de las relaciones de sucesos -además de estar guiadas a través de unas estructuras argumentales concretas- era facilitada a través de la inclusión de una serie de lugares comunes o imágenes recurrentes. Fénix, una vez convertida en capitán de bandoleros, ordenó la ejecución de una "mujer vieja" por ser "falsa en el decir" y "chismosa" (BC, F. Bon. 11797). La figura de la vieja astuta y chismosa también aparece en un Curioso romance, en que se declara, y da cuenta de la vida, enredo, y embustes de Doña Jacinta. La protagonista de los hechos acentúa esta cualidad cuando alcanza la vejez: "Pero viendo esta mujer/que se iba a villa vieja/(...).Ya que ser olla no pudo,/dispuso ser cobertera,/y así llevaba papeles,/engañando a muchas hembras" (BNE, VE 114/17). Otra situación recurrente con la que solían topar los lectores era la del encierro femenino, tal y como se observa en la relación de Sebastiana del Castillo (BC, F. Bon. 11889), así como en un Caso nuevamente acontecido, que da cuenta de cómo un caballero de una ciudad alemana intenta evitar la infidelidad de su esposa encerrando a ésta en una torre ${ }^{27}$ (BNE, R 100155(22) $)^{28}$. Varias de las publicaciones que forman parte del conjunto documental que estamos analizando emplean el motivo del asesinato nocturno, el cual suele ser perpetrado con la colaboración o acompañamiento de un hombre. Por ejemplo, Sebastiana del Castillo escribió un "papelillo" a Juan González del Pino para que acudiera a su casa la noche del asesinato de sus padres (BC, F. Bon. 11889).

En ocasiones, estas imágenes recurrentes hunden sus raíces en la Edad Media. Roger Chartier ha constatado que algunos ocasionales franceses -publicaciones muy

\footnotetext{
${ }^{27}$ Una versión más laxa de la idea de encierro es el simple control de movimientos. Así se refleja en una Letrilla en la que se dice dar algunos consejos para librarse de la locura de las mujeres: "Que yendo en mi compañía,/vea comedia algún día,/porque el permiso la di;/corra, eso sí, sí, sí, sí./Mas que salga disfrazada,/y de traje demudada,/con la vieja que buscó;/quita, eso no, no, no, no" (BNE, MSS 18108, H. 225-226). En la práctica, el encierro se producía fundamentalmente entre las clases urbanas medias y altas (Vigil, 1986: 27). En un contexto más general, durante la Alta Edad Moderna se establece con claridad la separación entre la esfera doméstica -propia de la mujer- y la vida pública -propia del hombre- (Walthaus, 1993: 72).

${ }^{28} \mathrm{R}$ (=Raros).
} 
parecidas a las relaciones de sucesos españolas- han encontrado su inspiración en La Leyenda dorada (c. 1260). Concretamente, el capítulo de la Natividad de la Bienaventurada Virgen María relata que unos verdugos no consiguieron decapitar a un reo porque la Virgen detenía los brazos cuando éstos se disponían a ejecutar la acción (Chartier, 1993b: 220-221). Consideramos que una relación publicada en Sevilla en 1678 estuvo influenciada directa o indirectamente por esta historia medieval. Un labrador avaricioso obtiene grandes beneficios aprovechándose de la carencia de trigo. Cuando una mujer que llega a su cortijo pidiendo limosna le anuncia buenas cosechas -lo cual perjudica sus intereses-, el hombre enfurece y levanta su brazo, pero éste queda paralizado: "Como si fuera de mármol/el brazo le quedó vuelto,/sin poder restituirlo/de ningún modo a su centro" (CBDRS) ${ }^{29}$.

Guillian Brown y George Yule abogan por la diferenciación de dos conceptos: la "entidad temática" o "personaje principal", por un lado, y el "tema del discurso", por otro lado (Brown y Yule, 1993: 169-174). De este modo, en las relaciones de sucesos que son objeto de estudio del presente trabajo, el "tema del discurso" no está constituido por las protagonistas de los diferentes relatos. La bandolera Fénix, Sebastiana del Castillo, Doña Teresa de Llanos, Camila, Antonia de Paz y la asesina de México son los personajes principales de sus respectivos textos. Pensamos que esta aclaración terminológica no es un asunto banal, sino que al hacerla somos más conscientes de los mecanismos discursivos que se ponían en funcionamiento en el terreno de la literatura de cordel. Por ejemplo, uno de los objetivos del impreso que narra las vicisitudes de Camila es trasladar al lector las nefastas consecuencias del amor pasional ${ }^{30}$. En lugar de elaborarse un complejo ensayo o tratado moral sobre la materia, que incluiría una serie de reflexiones teóricas, esta relación opta por construir la crítica al amor ilícito en base a un personaje concreto, más cercano para el lector desde el punto de vista psicológico.

Por último, el recurso al sensacionalismo forma parte de las estrategias discursivas de las relaciones de sucesos:

No olvidemos que estos textos están hechos también para una lectura pública, se dirigen a un auditorio poco culto $y$, mutatis mutandis, desempeñan el papel atrayente de cualquier publicación sensacionalista que se complace en dar detalles cuya repugnancia sirve para satisfacer e incentivar la imaginación de un público poco exigente en el plano cultural. Esa estrategia discursiva se inscribe en una finalidad de propaganda en la cual la caricatura y el exceso son fundamentales (Begrand, 2008: 30).

\footnotetext{
${ }^{29}$ CBDRS (=Catálogo y Biblioteca Digital de Relaciones de Sucesos).

${ }^{30}$ El concepto de amor durante la Edad Moderna está limitado por dos extremos: el amor humano como manifestación del amor divino y la consideración negativa del amor-pasión en tanto en cuanto perjudica a la razón (De la Pascua, 2006: 298).
} 
El sensacionalismo no es algo privativo de la literatura de cordel, sino que también lo emplearon otro tipo de publicaciones. Antonio Gil Ambrona ha llamado la atención sobre la vertiente morbosa de los añadidos que hace Juan Justiniano a la obra de Juan Luis Vives la Formación de la mujer cristiana, de tal manera que, en determinados fragmentos, el escrito del humanista valenciano se convierte en una "crónica de sucesos" (Gil Ambrona, 2008: 183-184 y 192) ${ }^{31}$.

En las relaciones de sucesos que estamos manejando, hay términos o expresiones que dan a los relatos un tono sensacionalista. Por ejemplo, en la historia de la asesina de México se habla de una "violenta muerte", de un "fin desgraciado" y de una "muerte sangrienta" (BNE, VE 1364/7). En esta misma línea, la bandolera Fénix comete numerosas "atrocidades" y protagoniza una "cruel muerte" (BC, F. Bon 11797). Incluso, hay pliegos sueltos que contienen descripciones sensacionalistas mucho más detallistas, como es el caso del asesinato ejecutado por Antonia de Paz: "Cogiendo la daga misma/de aquel infeliz amante,/y el corazón le partió,/y después con un alfanje/ le cortó brazos, y piernas,/y aún cortó para vengarse,/la cabeza, y sus vergüenzas,/los miembros echó en la calle" (BNE, MSS 18108). El asesinato de los padres de Sebastiana del Castillo a manos de su propia hija también se caracteriza por un marcado tremendismo, acentuado por la inserción del estilo directo en los diálogos:

Fue donde estaban sus padres/con un ánimo atrevido,/le dio cuatro puñaladas,/que el corazón le ha partido/al padre y luego a la madre/hizo con ella lo mismo,/porque con dos puñaladas/se la dejó sin sentido:/habló solo estas palabras,/y palpitando la dijo:/hija de mi corazón,/¿en qué te hemos ofendido?/La dice: señora madre,/esto es vengar mi castigo,/y con otra puñalada/concluyó a su vida el hilo:/les sacó los corazones,/y en aceite los ha frito (BC, F. Bon. 11889).

Evidentemente, los autores de las relaciones de sucesos emplearon todas estas estrategias discursivas para tratar de hacer llegar al público de las mismas un determinado mensaje. Es decir, el autor pretendía guiar la lectura (o la audición) de su relato para imponer así una serie de ideas. No obstante, y siguiendo a Roger Chartier, creemos que el proceso de transmisión de estos textos no era unidireccional, sino que habría que hablar de la existencia de un equilibrio entre la coacción ejercida por el autor y la libertad del lector ${ }^{32}$. Con todo, creemos que esta libertad del destinatario no

\footnotetext{
${ }^{31}$ Juan Justiniano fue el traductor y divulgador en España de la Formación de la mujer cristiana. La versión latina data del año 1523, mientras que la versión castellana de Justiniano -que incluía un extenso prólogo y adaptaba algunos pasajes- comenzó a circular por España a partir de 1528 (Morant Deusa, 2006: 35).

${ }^{32}$ Concretamente, Roger Chartier emplea dos términos para referirse a esta problemática: disciplina e invención, afirmando que hay que "transformar en tensión operatoria lo que podría parecer como una inseparable aporía: ese es el intento de una historia de las prácticas de lectura que, para cada época y cada medio, pretende identificar las modalidades compartidas del leer que sitúan los gestos individuales, y que pone en el centro de su interrogación los procesos por los que, frente a un texto, un lector o una comunidad de lectores produce una significación que le es propia" (Chartier: 1993b, 36 y $55)$.
} 
es total, puesto que en la apropiación del mensaje siempre juegan un papel muy importante los límites establecidos por el autor. Determinadas fuentes (como unas hipotéticas anotaciones realizadas por un lector a partir de la recepción de los pliegos sueltos) nos ayudarían a entender mejor ese proceso creativo de lectura, pero, en este caso, nosotros no contamos con documentos de estas características. Así las cosas, lo que sí podemos hacer es llevar a cabo una interpretación a partir de lo que nos dicen las propias relaciones de sucesos ${ }^{33}$.

Ya en los primeros versos, el autor del Curioso romance, en que se da cuenta de un maravilloso suceso, y caso prodigioso, que sucedió en la ciudad de Viterbo avisa al lector del valor ejemplarizante del impreso que tiene entre sus manos: "El Alto Espíritu Santo/alumbre mi entendimiento,/para que pueda contar/el más notable suceso./Que jamás ha sucedido/en los anales del tiempo,/para admiración del Orbe,/y de muchos escarmiento" (BNE, VE 113/13). La historia constituye una tajante crítica al amor pasional o amor ilícito, puesto que el amor obstinado que siente Camila hacia un hombre es lo que desencadenó una serie de desgracias ${ }^{34}$. No obstante, los lectores podían otorgar a esta publicación otras significaciones. La mitad de la primera plana del pliego está ocupada por un grabado xilográfico que representa a la Virgen de los Remedios. Como señala Armado Petrucci, una de las coordenadas que han de considerarse a la hora de estudiar la organización del espacio de escritura -aspecto que nos permite mejorar nuestro conocimiento de la historia de la lectura- es "la relación entre texto y figura" (Petrucci, 2002: 20). Por ello, dicho grabado no puede ser visto como un elemento meramente decorativo, sino que se trata de un componente que guía y conduce las posibles interpretaciones de los lectores. El resto del espacio de esta primera plana está destinado a la inserción del extenso título, el cual se cierra con la siguiente afirmación: "Dase cuenta cómo dieron en poder de moros, dónde él fue muerto, y ella cautiva, y del fin dichoso que tuvo por la devoción de la Virgen de los Remedios". La alusión a la Virgen de los Remedios vuelve a aparecer en la última estrofa de la composición: "Todos devotos seamos/de la Virgen, pues que vemos/que con su favor el alma,/para su dicha halló puerto" (BNE, VE 113/13). Por lo tanto, además de ser una crítica al amor pasional, el Curioso romance es un instrumento para la promoción de la imagen de una determinada Virgen. Por otra parte, el autor del escrito plantea a lo largo de los versos otra serie de cuestiones, como la importancia de salvaguardar el honor de las doncellas o la necesidad de concertar matrimonios entre personas de igual "calidad". En el momento de la apropiación del discurso, los diferentes lectores, ejerciendo su cuota de libertad, podían verse atraídos por uno u

\footnotetext{
${ }^{33}$ En este sentido, Carlos Alberto González Sánchez ha aludido a los límites impuestos por las fuentes a los propósitos de la Historia de la Cultura Escrita (González Sánchez, 2012).

${ }^{34}$ Henry Ettighausen, en un trabajo titulado "Sexo y violencia: noticias sensacionalistas en la prensa española del siglo XVII", analiza cuatro relaciones de sucesos en las que la pasión sexual ilícita conduce a asesinatos violentos (Ettinghausen, 1993).
} 
otro asunto. Incluso es posible que hubiese quien, simplemente, destacase las escenas sensacionalistas y sangrientas de la historia, sin prestar especial atención a los temas a los que acabamos de referirnos.

Algunos pasajes de los pliegos sueltos eran especialmente propicios para que el lector llevara a cabo una recreación mental de los mismos. Por ejemplo, la bandolera Fénix era la personificación de la promiscuidad sexual: "Si algún pasajero acaso/que le agradase encontraba,/por fuerza, o por grado hacía/que de su beldad gozara,/y después la muerte fiera/tiranamente le daba" (BC, F. Bon. 11797). En este sentido, Maria Grazia Profeti dice que "la escritura (...) incluye con sus juegos evocadores al destinatario, el cual (...) tiene que ser connivente y cómplice, ora descubriendo la alusión, ora recreando la escena erótica, ora gozando de la directa mención del cuerpo" (Grazia Profeti, 1993: 257).

Más allá de los asuntos propuestos por las diferentes relaciones de sucesos, creemos que es de capital importancia tomar en consideración una determinada vertiente de esta tipología textual, a saber, su utilización como instrumentos de evasión y de control social. Los relatos de la bandolera Fénix (BC, F. Bon. 11797), de Sebastiana del Castillo (BC, F. Bon. 11889) y de Doña Teresa de Llanos (BC, F. Bon. 20213) presentan unos hechos en los que la realidad social ha sido claramente trastocada o transgredida. En los tres casos la protagonista finge ser un hombre, lo que supone una alteración del orden social en lo relativo a la cuestión sexual. También se produce una situación de modificación de los roles sociales, ya que Fénix se convierte en capitán de bandoleros después de vengar el asesinato de su amante. Incluso, hallamos una situación inusual al comprobar cómo Teresa de Llanos es capaz de matar a sus dos hermanos en un duelo a espada, lo que supone conceder a las mujeres unas habilidades o destrezas con las que, según el pensamiento de la época, no contaban ${ }^{35}$. En cualquier caso, estas situaciones de transgresión social, en el fondo, al presentar un "mundo al revés", no harían sino afirmar la situación de desigualdad de las mujeres, de ahí que hablemos de mecanismos de control y reproducción social.

Como señala Rina Walthaus -refiriéndose al siglo XVI-, "la cultura, la literatura y, con ello, el teatro (...) forman parte del discurso y de los códigos patriarcales vigentes en la sociedad de aquel entonces. Son canales que en un complejo proceso de interacción reflejan e imponen las ideas vigentes acerca de lo que es o lo que debe ser lo masculino y lo femenino" (Walthaus, 1993: 73). Añadiríamos que ese discurso no solamente proyecta las ideas imperantes, sino que también influye en la construcción

\footnotetext{
${ }^{35}$ Nos parece muy interesante la reflexión que hace Rina Walthaus en torno a la figura de la mujer fuerte y varonil. En las obras teatrales de Juan de la Cueva y Cristóbal de Virués - dos autores de la segunda mitad del siglo XVI- este tipo de mujer responde a una "fantasía masculina" no carente de “provocación y erotismo" (Walthaus, 1993: 74).
} 
de la realidad social. Y todo ello se lleva a cabo a través de unas determinadas estrategias discursivas.

\section{Conclusiones}

Indudablemente, la invención de la imprenta dio lugar a una importancia creciente de lo escrito. No obstante, el universo de lo oral tiene un peso muy importante a lo largo de la Edad Moderna. La transmisión oral de la literatura de cordel -que se une a su difusión a través de la palabra impresa- se sitúa en un contexto general en el que lo pregonado, lo recitado, lo cantado y los rumores juegan un papel crucial. Tal y como ha indicado Clara Bejarano Pellicer, una figura prototípica de la ciudad del Antiguo Régimen es la del pregonero, quien difundía entre la población informaciones de todo tipo (económicas, políticas y festivas) (Bejarano Pellicer, 2010). En los Avisos de José de Pellicer Ossau de Tovar (1602-1679) hay numerosas alusiones a los rumores que circulaban entre las altas esferas de la sociedad. Por ejemplo, en un aviso del 15 de noviembre de 1639 dice que "corre voz de que se quiere formar un nuevo Consejo en Rota...", mientras que el 20 de diciembre de ese mismo año anuncia que "hay rumor de que saldrá un día de éstos no sé qué novedad tocante a la moneda de plata y oro $^{\prime 36}$. El estudio de la transmisión oral de la literatura de cordel ha de ponerse en relación con otras voces y ruidos que se escuchaban en las calles de las poblaciones tanto urbanas como rurales- del Antiguo Régimen. $Y$ todo ello ha de encuadrarse en lo que Peter Burke denomina "historia de los sentidos" (Burke, 2005: 136).

Detectamos una homogeneidad en las estrategias discursivas empleadas por las relaciones de sucesos de temática femenina, las cuales están situadas en el terreno de la literatura del exemplum y en el ámbito de los productos de evasión. La microhistoria dará los frutos deseados siempre y cuando la pongamos en relación con un contexto general. Evidentemente, otros pliegos de cordel de temática diferente también están situados en estos parámetros. En un contexto aún más general, las relaciones de sucesos, ejemplarizantes y evasivas, hay que ponerlas en conexión con otros espectáculos de masas, como por ejemplo el teatro y el carnaval.

Uno de los grandes problemas a los que se enfrenta la Historia de la Cultura Escrita es el de las fuentes. Esta disciplina historiográfica concede un gran protagonismo a la recepción de lo escrito por parte de los destinatarios. No obstante, en ocasiones no contamos con aquellos testimonios que nos permitirían hacer afirmaciones más contundentes acerca de las significaciones que los lectores/oyentes extraen de los textos. Con todo, tenemos la posibilidad de realizar interpretaciones a partir de los

\footnotetext{
${ }^{36}$ Hemos empleado la edición de Jean-Claude Chevalier y Lucien Clare (2002).
} 
recursos disponibles, siempre y cuando intentemos no caer en una subjetividad extrema.

\section{Fuentes y Bibliografía}

\section{Fuentes}

Caso nuevamente acontecido en una ciudad de Alemania llamada Ayrleuen, a un caballero, que pidiendo a un quiromante que le dijese su ventura, y rehusándole cuanto pudo, por ver señales en el caballero de cornudo, se lo hubo de decir por su importunación. Y cómo hizo hacer una torre muy fuerte para encerrar en ella a su mujer por estar seguro. Y lo que de ello sucedió la historia lo dirá muy extenso. Traducida en verso castellano, s.I., s.i., s. XVI?, 8 p., 8o, BNE, R $100155(22)^{37}$.

Curiosa jácara nueva, que hace relación de una rara crueldad, cometida por una mujer, sucedida en la ciudad de Huesca, Reino de Aragón; y fue, que la dicha mujer dio alevosa muerte a un caballero, y después tiranamente le cortó sus miembros con el ardid que aquí se refiere. Declárase el ejemplar castigo que de ella hicieron en la dicha ciudad, s.I., s.i., entre 1700-1799, 4 p., 40, BNE, MSS 18108 (H. 231$232)^{38}$.

Curioso romance, en que se declara, y da cuenta de la vida, enredos, y embustes de Doña Jacinta, cuyo apellido se deja al silencio; refiérense sus muchas maldades, y tacañerías que hacía con diferentes hombres, y mujeres de esta Corte; usurpándoles el dinero, y engañándoles, trayendo muchas personas revueltas: y del castigo ejemplar que se ejecutó en su persona el día ocho de febrero de 1687 saliendo con doscientos tocinos a las espaldas, y una coroza muy reverenda. Con lo demás que verá el curioso lector, s.I., s.i., 1687?, 2 h., 4으, BNE, VE 114/17.

Curioso romance, en que se da cuenta de un maravilloso suceso, y caso prodigioso, que sucedió en la ciudad de Viterbo a primero de enero de este presente año, y fue que una desalmada mujer mató a su marido, y a una tía suya, y les sacó el corazón, por gozar de un mancebo que tenía por galán, con el cual se salió. Dase cuenta cómo dieron en poder de moros, dónde él fue muerto, y ella cautiva, y del

\footnotetext{
${ }^{37}$ Hemos consultado una edición facsímil contenida en: GARCÍA DE ENTERRÍA, Mạ C. (1973): Pliegos poéticos españoles en la Biblioteca Ambrosiana de Milán, Madrid, Joyas Bibliográficas.

${ }^{38}$ La cronología aproximada de las relaciones de la Biblioteca Nacional de España la hemos tomado de la descripción contenida en el catálogo de dicha biblioteca.
} 
fin dichoso que tuvo por la devoción de la Virgen de los Remedios, s.l., s.i., 16--?, 4 p., 4, BNE, VE 113/13.

Curioso romance, y verdadera relación de un maravilloso prodigio, que para escarmiento de los logreros, le sucedió a un labrador en un cortijo, que llaman el Rubio, que está entre Archidona, e Isnajar; dase cuenta de cómo al tiempo que una mujer le llegó a pedir limosna, y le dijo, que nuestro señor había de darnos una gran cosecha de trigo; respondiendo que hacia atrás, al levantar la mano, y el brazo para hacer la acción, se le quedó mano, y brazo levantado, y vuelto a las espaldas por encima del hombro, y la mujer se desapareció; cuyo caso sucedió este año de 1678 el último día del mes de abril, Sevilla, Juan Cabezas, 1678, 4 p., Fondo fotográfico donado por María Cruz García de Enterría al grupo SIELAE, Catálogo y Biblioteca Digital de Relaciones de Sucesos (siglos XVI-XVIII). Disponible en Internet (8-3-2013): www.bidiso.es/relaciones

Curioso y nuevo romance, en que se refiere la violenta muerte que dio una mujer a su marido por estar amancebada con un soldado, el fin desgraciado que ella tuvo y el prodigio que obraron las benditas ánimas con el soldado su devoto. Sucedió en México en este presente año, Málaga, Imprenta y Librería de D. Félix de Casa y Martínez, entre 1781-1805?, 4 p., 4으, BNE, VE 1364/7.

Jácara nueva, en que se refiere un lastimoso caso, que sucedió a una doncella de la ciudad de Trujillo, a la cual un amante suyo le sacó de su casa, engañada con palabra de casamiento, dejándole después en Sierra Morena: y el ejemplar castigo que en él, y a un primo suyo se ejecutó, como lo verá el curioso lector, Barcelona, herederos de Juan Solís, 1760?, 4p., 4ํ, BC, F. Bon. $4364^{39}$.

Jácara nueva, en que se refiere un lastimoso caso, que sucedió a una doncella de la ciudad de Trujillo, a la cual un amante suyo le sacó de su casa, engañada con palabra de casamiento, dejándole después en Sierra Morena: y el ejemplar castigo que en él, y a un primo suyo se ejecutó, como lo verá el curioso lector, Barcelona, Francisco de Ifern y Oriol, c. 1804, 4 p., 4ํ, BC, F. Bon. 4455.

Jácara nueva, en que se refiere, y da cuenta de veinte muertes que una doncella Ilamada Doña Teresa de Llanos, natural de la ciudad de Sevilla, siendo las primeras a dos hermanos suyos, por haberle estorbado el casarse. Y también se declara cómo se vistió de hombre, y fue presa, y sentenciada a muerte, y se vio libre por haberse descubierto que era mujer y el dichoso fin que tuvo, Barcelona, herederos de Juan Solís, 1760?, 4p., 4ํ, BC, F. Bon. 20213.

\footnotetext{
39 La cronología aproximada de las relaciones de la Biblioteca de Catalunya la hemos tomado de la descripción contenida en el catálogo de dicha biblioteca.
} 
Letrilla graciosa, y nueva. Compuesta por un astrólogo moderno, que alcanza grande ciencia en las influencias del signo de Capricornio; y avisa a todos los casados del modo que podrán librarse de las demasías, y locuras de sus mujeres. Y un romance de las amistades fingidas, y de las verdaderas, y seguras, s.l., s.i., entre 1700-1799, 4 p., 4으, BNE, MSS 18108 (H. 225-226).

MENDOZA, J. de: Verdadera Relación, y curioso romance, que declara la vida, y atrocidades de una valiente mujer llamada Fenix, la cual dio cruel muerte al mismo que mató su amante, y después se hizo Capitán de bandoleros. Dase cuenta del dichoso fin que tuvo. Con lo demás que verá el curioso. Sucedió este presente año, Calatayud, Juan Aguirre, c. 1780, 4 p., 4ํ, BC, F. Bon. 11797.

PELLICER DE TOVAR, J.: Avisos, edición de Jean-Claude Chevalier y Lucien Clare, París, Éditions Hispaniques, 2002.

Sebastiana del Castillo: nuevo, y curioso romance, en que se declaran las atrocidades de Sebastiana del Castillo: refiérese cómo mató a su padre, y su madre, y a dos hermanos suyos, porque la tuvieron encerrada más de un año, guardándola de su amante; y el castigo que en ella se ejecutó en Ciudad-Rodrigo: con lo demás que verá el curioso lector, Madrid, Andrés de Sotos, c. 1775, 4 p., 4으, BC, F. Bon. 11889.

Verdadera relación, y curioso romance, en que se declara el donoso chiste, y graciosa burla, que les jugó una señora en la Villa de Madrid, a un portugués zapatero remendón, y a un francés aguador, porque la quebraban de amores. Dase cuenta cómo les quitó los doblones, y tuvo traza para sacarlos a la Plaza metidos en un arca, en forma del Totili-mundi. Y lo demás que verá el curioso lector, Barcelona, Juan Forns, c. 1760, 4 p., 4으, BC, F. Bon. 4380.

\section{Bibliografía}

AGULLÓ Y COBO, M. (1966): Relaciones de sucesos. I, Años 1477-1619, Madrid, CSIC.

ARROYO RODRíGUEZ, L. A. (1999): “Las mercancías de un vendedor de pliegos de cordel de la segunda mitad del siglo XVI", en Bulletin Hispanique, no101, 1, 1999, pp. 247-251.

ASENSIO RUBIO, M. (1988): “Ordenamiento jurídico y realidad social de las mujeres en Ciudad Real (s. XVII-XVIII): aproximación a una realidad desconocida", en Asensio Rubio, M. (et al.), I Congreso de Historia de Castilla-La Mancha. Tomo VIII: Conflictos sociales y evolución económica en la Edad Moderna (2), Toledo, Servicio de Publicaciones de la Junta de Comunidades de Castilla-La Mancha, pp. 105-111. 
BEGRAND, P. (2008): "Las figuras del renegado y del mártir, metáforas del infierno y del paraíso", en Civil, P., Cremoux, F. y Sanz, J. (editores), España y el mundo mediterráneo a través de las relaciones de sucesos (1500-1750), Actas del IV Coloquio Internacional sobre Relaciones de Sucesos (París, 23-25 de septiembre de 2004), Salamanca, Ediciones Universidad de Salamanca, pp. 25-39.

BEJARANO PELLICER, C. (2010): “Medios de comunicación en la ciudad durante la Edad Moderna: la figura del pregonero", en Castillo Gómez, A. y Amelang, J. (directores) y Serrano Sánchez, C. (editora), Opinión pública y espacio urbano en la Edad Moderna, Gijón, Trea, pp. 319-334.

BROWN, G. y YULE, G. (1993): Análisis del discurso, Madrid, Visor Libros.

BURKE, P. (2005): ¿Qué es la historia cultural?, Barcelona, Paidós.

CARO BAROJA, J. (1990) [1969]: Ensayo sobre la literatura de cordel, Madrid, Istmo.

CASTILlO GÓMEZ, A. (2005): "La corte de Cadmo. Apuntes para una historia social de la cultura escrita", en Revista de Historiografía, nํㄴ, II, 2/2005, pp. 18-27.

CHARTIER, R. (1993a): "De la historia social de la cultura a la historia cultural de lo social", en Historia Social, nำ17, 1993, pp. 97-103.

- (1993b): Libros, lecturas y lectores en la Edad Moderna, Madrid, Alianza.

- (1992): El mundo como representación, Barcelona, Gedisa.

DE LA PASCUA, Mạ J. (2006): "Las relaciones familiares. Historias de amor y conflicto", en Morant Deusa, I. (directora), Historia de las mujeres en España y en América Latina (II). El mundo moderno, Madrid, Cátedra, pp. 287-315.

DI PINTO, E. (2010): “Jácaras de sucesos: otra modalidad (EI Caso en jácaras)", en Díez Borque, J. Ma (director), Cultura oral, visual y escrita en la España de los Siglos de Oro, Madrid, Visor, pp. 217-241.

ESPEJO CALA, C. (2000): "La cultura del impreso: un nuevo espacio cultural para el desarrollo propagandístico de la Alta Edad Moderna", en Espejo Cala, C. (coordinadora), Propaganda impresa y construcción del Estado moderno y contemporáneo, Sevilla, Alfar, pp. 9-26.

ETTINGHAUSEN, H. (2012): "Prensa amarilla y barroco español”, en Chartier, R. y Espejo, C. (editores), La aparición del periodismo en Europa. Comunicación y propaganda en el Barroco, Madrid, Marcial Pons, pp. 127-157.

- (1993): "Sexo y violencia: noticias sensacionalistas en la prensa española del siglo XVII", en Edad de Oro, XII, 1993, pp. 95-107. 
FRENK, M. (1984): "Ver, oír, leer...", en Schwartz Lerner, L. y Lerner, I. (editoras): Homenaje a Ana María Barrenechea, Madrid, Castalia, pp. 235-240.

GARCÍA DE ENTERRÍA, Ma C. (1999): “¿Lecturas populares en tiempos de Cervantes?”, en Castillo Gómez, A. (compilador), Barcelona, Gedisa, pp. 345-362.

- (1988): “Romancero: ¿cantado-recitado-leído?”, en Edad de Oro, VII, 1988, pp. 89-104.

- (1973): Sociedad y poesía de cordel en el Barroco, Madrid, Alianza.

GARCÍA DE ENTERRÍA, Mạ C. y MARTÍN ABAD, J. (directores) (1998): Catálogo de pliegos sueltos poéticos de la Biblioteca Nacional: siglo XVII, Madrid, Universidad de Alcalá-Biblioteca Nacional.

GIL AMBRONA, A. (2008): Historia de la violencia contra las mujeres. Misoginia y conflicto matrimonial en España, Madrid, Cátedra.

GOMIS COLOMA, J. (2010): "Intermediarios entre el texto y su público: la cofradía de pobres ciegos oracioneros de Valencia”, en Castillo Gómez, A. y Amelang, J. (directores) y Serrano Sánchez, C. (editora), Opinión pública y espacio urbano en la Edad Moderna, Gijón, Trea, pp. 301-317.

GONZÁLEZ SÁNCHEZ, C. A. (2012): "Cultura escrita y Nueva Historia Cultural: paradigmas y realidades", en Erebea. Revista de Humanidades y Ciencias Sociales, nำ, 2012, pp. 5-27.

GONZALO GARCÍA, C. (2010): La biblioteca del relacionero: repertorios, catálogos y otras fuentes de información para la localización de las relaciones de sucesos (BIRESU), A coruña, SIELAE.

GRAZIA PROFETI, M. (1993): “Mujer y escritura en la España del Siglo de Oro”, en Zavala, I. M. (coordinadora): Breve historia feminista de la literatura española (en lengua castellana). II La mujer en la literatura española: modos de representación desde la Edad Media hasta el siglo XVII, Barcelona, Anthropos, Madrid, Comunidad de Madrid, pp. 235-284.

LÓPEZ-CORDÓN, Mạ V. (1998): “Familia, sexo y género en la España moderna”, en Studia historica. Historia moderna, no18, 1998, pp. 105-134.

LORENZO CARDOSO, P. L. (1989): "Los malos tratos a las mujeres en Castilla en el siglo XVII", en Brocar: Cuadernos de investigación histórica, no15, 1989, pp. 119-136.

MORANT DEUSA, I. (2006): "Hombres y mujeres en el discurso de los moralistas. Funciones y relaciones", en Morant Deusa, I. (directora), Historia de las mujeres 
en España y en América Latina (II). El mundo moderno, Madrid, Cátedra, pp. 2761.

ORTEGA, M. (1989): "Algunas ideas vertidas sobre la mujer en el Consejo Supremo de Aragón durante el siglo XVII", en Maquieira d'Angelo, V. (editora), Actas de las VII Jornadas de Investigación Interdisciplinaria. Mujeres y hombres en la formación del pensamiento occidental, I, Madrid, Ediciones de la Universidad Autónoma de Madrid, pp. 173-183.

PENA SUEIRO, N. (2001): "Estado de la cuestión sobre el estudio de las Relaciones de sucesos", en Pliegos de Bibliofilia, no13, 2001, pp. 43-66.

PETRUCCI, A. (1999): Alfabetismo, escritura, sociedad, Barcelona, Gedisa.

- (2002): La ciencia de la escritura. Primera lección de Paleografía, Buenos Aires, Fondo de Cultura Económica.

PORRO HERRERA, Ma J. (1995): Mujer "sujeto"/mujer "objeto" en la literatura española del Siglo de Oro, Málaga, Secretariado de Publicaciones e Intercambio Científico de la Universidad de Málaga.

SÁNCHEZ-PÉREZ, M. (2008): "La poética de las relaciones de sucesos tremendistas en pliegos sueltos poéticos (siglo XVI): construcción y reelaboración", en Etiópicas: revista de letras renacentistas, $\mathrm{n}=4,2008$, pp. 1-20. Disponible en Internet (8-32013): www.uhu.es/programa_calidad_literatura_amatoria/etiopicas.htm.

SUÁREZ ROBAINA, J. R. (2003): El personaje mujer en el Romancero Tradicional (Imagen, amor y ubicación), Las Palmas de Gran Canaria, Ediciones del Cabildo de Gran Canaria.

UGARTE, J. (2005): "Sobre la nueva historia cultural: entre el "giro cultural» y la ampliación del conocimiento histórico", en Hernández Sandoica, E. y Langa, A. (editoras), Sobre la Historia actual. Entre política y cultura, Madrid, Abada, pp. 229-283.

VAN DIJK, T. A. (2001): "El discurso como interacción en la sociedad", en Van Dijk, T. A. (compilador), El discurso como interacción social. Estudios sobre el discurso II. Una introducción multidisciplinaria, Barcelona, Gedisa, pp. 19-66.

VÁZQUEZ GESTAL, P. (2001): “Despegándose del texto. Los juegos de la "Nueva Historia Cultural": Descripción, narración e interpretación", en Memoria y Civilización, no4, 2001, pp. 151-186.

VIGIL, M. (1986): La vida de las mujeres en los siglos XVI y XVII, Madrid, Siglo XXI. 
WALTHAUS, R. (1993): “Entre Diana y Venus: mujeres castas y mujeres fatales en el teatro de Juan de la Cueva y Cristóbal de Virués", en Walthaus, R. (directora): La mujer en la literatura hispánica de la Edad Media y el Siglo de Oro, Ámsterdam, Rodopi, pp. 71-90. 